\title{
APPLICATION FOR THE ELECTROCATALYTIC OXIDATION AND AMPEROMETRIC DETERMINATION OF GLUCOSE USING A COMPOSITE OF NICKEL HEXACYANOFERRATE INTEGRATED GRAPHENE AND p-PARAPHENYLENEDIAMINE
}

\author{
Jadhav Varsharani Shankar ${ }^{1}$, Raghu Subashchandrabose ${ }^{2}$, Shanmugaraj \\ Andikkadu Masilamani ${ }^{2}$ and Kalaivani Raman ${ }^{1 *}$ \\ ${ }^{1}$ Department of Chemistry, VISTAS, Pallavaram, Chennai-600117, TamilNadu, India. \\ ${ }^{2}$ Centre for Advanced Research \& Development, VISTAS, Chennai-600117 TamilNadu, India \\ *E-mail: rakvani@yahoo.co.in
}

\begin{abstract}
In this work, a stable electro active thin film of Nickel hexacyanoferrate (NiHCF) was placed on the surface of a Graphene and p-Peraphenylenediamine composite electrode using a humble method. Cyclic voltammetric experiments presented two pairs of well-defined peaks for this NiHCF modified electrode which displayed excellent electrocatalytic possessions for the oxidation of glucose at a reduced over potential of $50 \mathrm{mV}$ and over a concentration range of $3.33 \times 10(-6)$ to $1.0 \times 10(-3) \mathrm{M}$ with a slope of 0.208 micro $\mathrm{A} / \mathrm{micro} \mathrm{M}$ with respectable sensitivity. The effect of the supporting electrolyte on peak current and peak potential were also gained in addition with effects of common meddling on the response of the improved electrode. Various parameters that influence the electrochemical behavior of the improved electrode were heightened by varying scan rates and $\mathrm{pH}$. In the Electrochemical impedance spectroscopy studies recommended that the electrode reaction of the NiHCF film is mainly controlled by transport of counter ion and immobilized NiHCF preserved its redox activity presenting a surface controlled electrode reaction with the electron transfer. The results of the differential pulse voltammetry (DPV) using the modified electrode was applied for the determination of glucose, in the commercially obtainable drugs. The results obtained expose that the electrode under study could be used as an effective sensor for online nursing of glucose.
\end{abstract}

Keywords: nickel hexacyanoferrate, modified electrode, amperometric determination, graphene, $p$ paraphenylenediamine

(C) RASĀYAN. All rights reserved

\section{INTRODUCTION}

In both the chemical and pharmaceutical industry having attention in the compound of Glucose. mainly, saccharide identification magnetizes the concentration of biochemists and medicinal chemists not only for the reason that saccharides are complicated in cell-cell communications within biological creatures other than also because saccharide sensing offers to assure for medical analytical applications such a blood sugar level, ${ }^{\mathbf{1}}$ pathogens, and cancer. In earth carbohydrates are the most abundant in the organic system of material, figures biological construction blocks plus dietary mechanisms, are classified as single sugars (monosaccharides) and their polymers, namely oligosaccharides and polysaccharides. In living organisms, Monosaccharides are most commonly and the humblest and most basic of carbohydrates, allocating both as energy fuels and primary elements. For illustration, five-carbon sugars are present in information carriers, for example, deoxyribose in DNA and ribose in RNA. D-glucose is the finest known 6-carbon sugars, also known as whichever sugar of grape or sugar of blood. milk sugar formation occurs when Dfructose, fruit sugar; and D-galactose are combined with glucose. ${ }^{2-5} \mathrm{~A}$ range of saccharides-related

Rasayan J. Chem., 11(3), 967-972(2018)

http://dx.doi.org/10.31788/RJC.2018.1133034

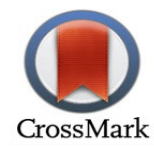


diseases are familiar in clinical practice, include, Splendour disease (acid maltase deficiency), fatness, hypoglycaemia, hyperactivity (mostly in children), and diabetes. ${ }^{6,7}$.

All the overhead qualities craft their detection and quantitation problems of considerable logical attention. As significance, current movement has been directed headed for the improvement of sensitive and discerning analytical technique for the determination of Glucose in a variety of sample matrices. There are so many other methods also existing for the quantitative determination of glucose from different matrices. in recent times metal hexacyanoferrates have also established applications in electrochromic, electrocatalysis, ion exchange selectivity, corrosion protection, etc. to develop sensors and biosensors. ${ }^{8}$ There as various methods such as adsorption, covalent binding, polymer coating, sol-gel, screen-printing and mixtures in Chemically modified electrodes. Recently Chemically modified electrodes is a dynamic area of research. So many methods are informed to prepare chemically improved electrodes. We here a new-fangled approach for the fabrication of a surface modified nickel hexacyanoferrate electrode using a PPD functionalized graphite powder. Cyclic voltammetry and electrochemical impedance methods were used for the electrochemical characterization of the modified electrode. ${ }^{9-15}$ The purpose of nickel hexa cyanoferrate surface modified electrode towards electro catalytic oxidation of Glucose was investigated. The manufacturing procedure was brought into being to be humble, reproducible, cost-effective and the sensor exhibits good sensitivity and reproducibility for the purpose of glucose. ${ }^{16-20}$

\title{
Chemicals \& Reagents
}

\section{EXPERIMENTAL}

Graphite powder (1-2 lm) and glucose were purchased from Aldrich Chemicals, All other reagents were of analytical grade. All aqueous solutions were prepared using distilled water. Studies on the effect of $\mathrm{pH}$ were carried out using $0.1 \mathrm{M} \mathrm{HCl}$ and $0.1 \mathrm{M} \mathrm{NaOH}$ solutions. p-Phenylenediamine (PPD) solution (10 $\mathrm{mM}$ ) and $0.01 \mathrm{M}$ of nickel solution were prepared by dissolving a suitable amount in dry ethanol and dry dimethylformamide (DMF), respectively.

\begin{abstract}
Apparatus
By using three-electrode configuration electrochemical measurements were completed using a workstation $\mathrm{CH}$ Instruments of Electrochemical (750). In a cell of the volume of $100 \mathrm{ml}$, All electrochemical experiments were carried out. The working electrode was surface modified NiHCF graphite wax composite. A platinum wire was used as the counter with a standard calomel electrode, an $\mathrm{Ag} / \mathrm{AgCl}$ used as standard reference electrode. The complete cell was preparedly connected to electrochemical workstation $\mathrm{CH}$ Instruments. The working electrode was a $3 \mathrm{~mm}$ diameter NiHCF graphite composite electrode.
\end{abstract}

\section{Fabrication of modified electrodes}

Initially, Hummers' method used to prepare GO from spectral graphite. Second, with a slight change, GR was obtained according to the reported technique. In a $10 \mathrm{~mL}$ glass vial $1.0 \mathrm{~mL}$ of GO aqueous solution $(1.0 \mathrm{mg} / \mathrm{mL}), 0.9 \mathrm{~g}$ of graphite, $3.0 \mathrm{~mL}$ of glucose solution $(80 \mathrm{wt} \%$ in distilled water) and the $1.0 \mathrm{~mL}$ of ammonia solution ( $28 \mathrm{wt} \%$ in distilled water) was added In a typical procedure for the chemical conversion of GO to GR. the airproofed and put into a constant temperature $\left(95^{\circ} \mathrm{C}\right)$ for $10 \mathrm{~h}$ After being vigorously shaken for $1 \mathrm{~h}$. By using ultra-pure distilled water the resulting precipitate was collected by centrifugation, and washed subsequent to uniform mixing of $30 \mathrm{~min}$. At room temperature, the purified solid was dried. By using a conventional method Modified carbon paste was prepared. To final paste collected precipitates were a suitable amount of silicone oil in a filling for $40 \mathrm{~min}$. At one end of a glassy carbon tube $(\mathrm{d}=3 \mathrm{~mm})$, a portion of the obtained carbon paste was filled and copper wire was inserted through the opposite end to assemble an electrical contact.

\section{RESULTS AND DISCUSSION}

FESEM image of nickel hexacyanoferrate surface modified graphene with PPD composite electrode shown in Fig.-1A was used to characterize their morphological structures, respectively, FESEM expressions a layer of film with scraggy and a rough surface, which delivers large reaction surface. 
Figure-1B shows that HRTEM nickel hexacyanoferrate modified graphene with PPD composite electrode. The structure as large thick dark flakes. NiHCF increases with the number of layers transferred on the electrode..$^{21-24}$
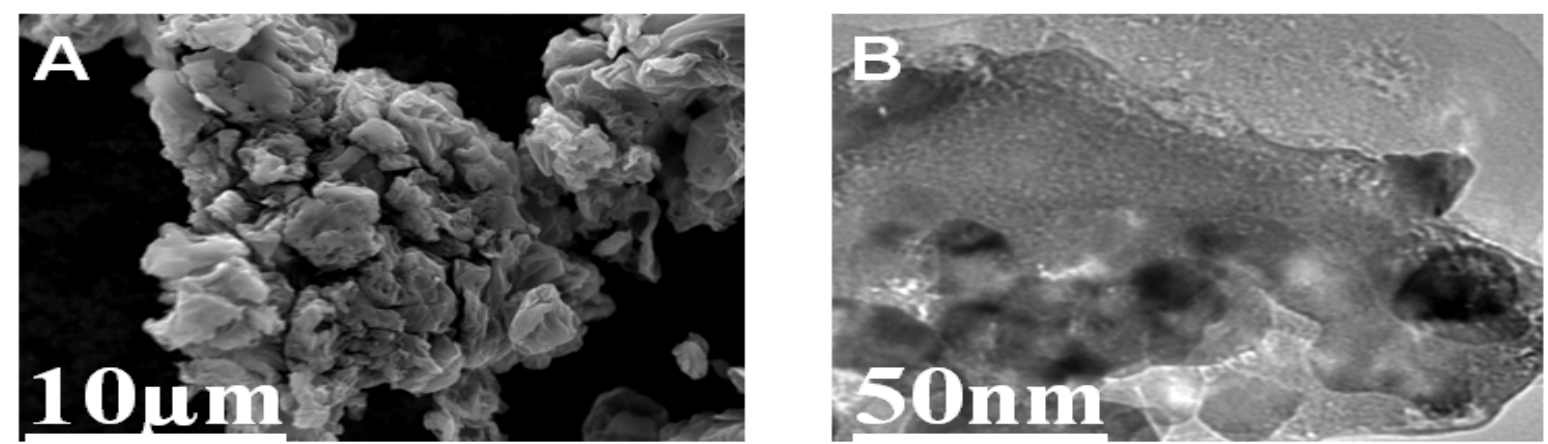

Fig.-1(A.): FESEM image of nickel hexacyanoferrate modified graphene with PPD composite electrode,

(B.) HRTEM image of nickel hexacyanoferrate modified graphene with PPD composite electrode.

Nickel hexacyanoferrate (NiHCF) layers voltammetrically arranged in a solution of $0.5 \mathrm{mM} \mathrm{NiCl} 2$ and $0.5 \mathrm{mM} \mathrm{K} \mathrm{K}_{3} \mathrm{Fe}(\mathrm{CN})_{6}{ }^{25}$ Figure-2A (arcs a and b) represents the typical cyclic voltammograms of the bare and the NiHCF modified electrode in $0.1 \mathrm{M} \mathrm{NaCl}$ medium. Redox peaks with proper potentials $0.25 \mathrm{~V}$ and $0.33 \mathrm{~V}$ vs. $\mathrm{Ag} / \mathrm{AgCl}$ experiential. ${ }^{30-32}$

\section{Effect of supporting electrolyte on the NiHCF modified electrode}

The manufacture of the NiHCF modified electrode fabricated was characterized as Explained: Cyclic voltammograms scans were showed in an unstirred solution of $0.1 \mathrm{M} \mathrm{NaCl}$ at a scan rate of $50 \mathrm{mVs}^{-1}$ in the potential range of 0 to $1.0 \mathrm{~V} v s \mathrm{Ag} / \mathrm{Agcl},{ }^{33}$. Figure-2B represents the electrochemical performance of the NiHCF modified electrode at altered scan rates from 10 to $100 \mathrm{mVs}^{-1}$ in $0.1 \mathrm{M} \mathrm{NaCl}$ electrolyte in the potential range of $1.0 \mathrm{~V}$ vs. $\mathrm{Ag} / \mathrm{AgCl}$ was studied ${ }^{34-35}$. Together the anodic, as well as cathodic peaks currents for both the redox pairs, were proportional to the square root of the scan rate the redox processes occurring at the modified electrode are dispersion skillful. This reveals that in the range examined $\mathrm{pH}$ has no considerable effect on the voltammetric response of the NiHCF modified electrode
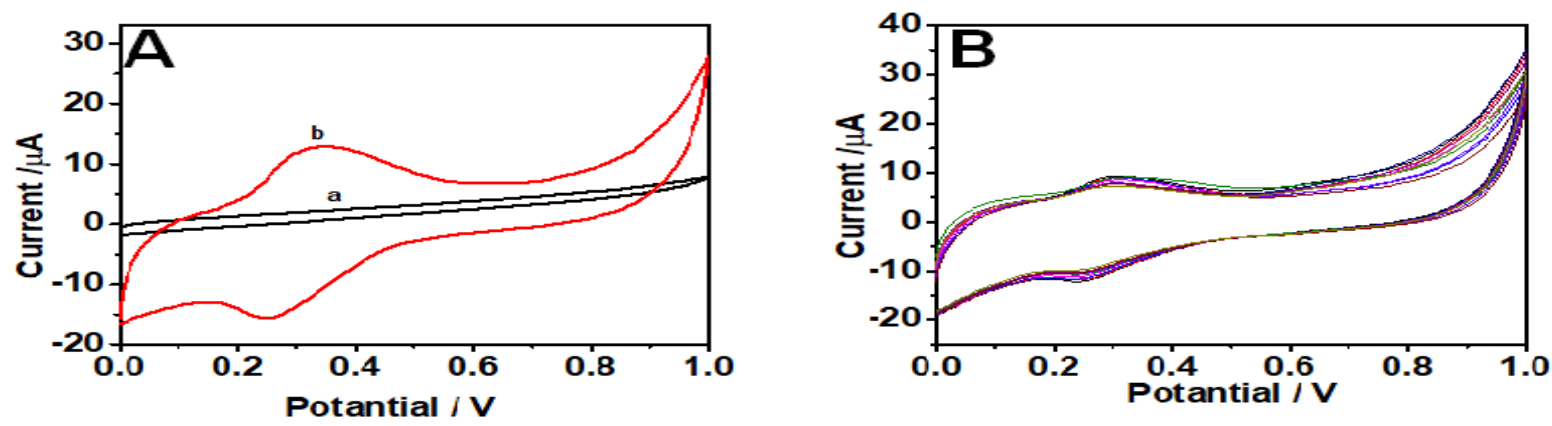

Fig.-2(A): Cyclic voltammograms electrodeposition of (a) bare electrode and (b)nickel hexacyanoferrateelectrode noted at $50 \mathrm{mV} \mathrm{s}^{-1}$ in $0.1 \mathrm{M} \mathrm{NaCl}(\mathrm{pH} \mathrm{7.0)}$, (B) The Cyclic voltammograms of electrodeposition of nickel hexacyanoferratesurface modified graphene with PPD composite electrode at scan rate of $50 \mathrm{mV} / \mathrm{s} \mathrm{in} 0.1 \mathrm{M} \mathrm{NaCl}$ electrolyte( $\mathrm{pH} 7.0)$.

The comparisons of the electrochemical behavior for NiHCF electrode, NiHCF modified electrode and a NiHCF modified electrode with $0.25 \mu \mathrm{M}$ at altered scan rates from 10 to $100 \mathrm{mVs}^{-1}$ in $0.1 \mathrm{M} \mathrm{NaCl}$ electrolyte in the potential range $1.0 \mathrm{~V}$ vs. $\mathrm{Ag} / \mathrm{AgCl}$.

\section{Electrocatalytic Oxidation of Glucose}

The electrocatalytic property showed by the NiHCF modified electrode for oxidation of Glucose in $0.1 \mathrm{M}$ $\mathrm{NaCl}$ is also exposed in Fig.-3B. It is seen that on bare graphite electrode, the oxidation of $0.25 \mu \mathrm{M}$ 
glucose arises at a higher potential around $0.35 \mathrm{~V}$ whereas on the NiHCF modified electrode, the oxidation of Glucose occurs at about $0.25 \mathrm{~V}$. The $\mathrm{CV}$ responses of different scan rates are shown in Fig.3B. it can be seen that the both anodic $\left(\mathrm{I}_{\mathrm{pa}}\right)$ and cathodic $\left(\mathrm{I}_{\mathrm{pc}}\right)$ peak currents enlarged linearly with increasing the scan rates from 10 to $100 \mathrm{mVs}^{-1}$. At the scan rate of $50 \mathrm{mVs}^{-1}$, Since, the low peak separation $(50 \mathrm{mV})$ at scan rate $10 \mathrm{mV} / \mathrm{s}$ and $\mathrm{I}_{\mathrm{pa}}$, $\mathrm{I}_{\mathrm{pc}}$ ratio becomes equal to the unity of surface type behavior appeared at the modified electrode.
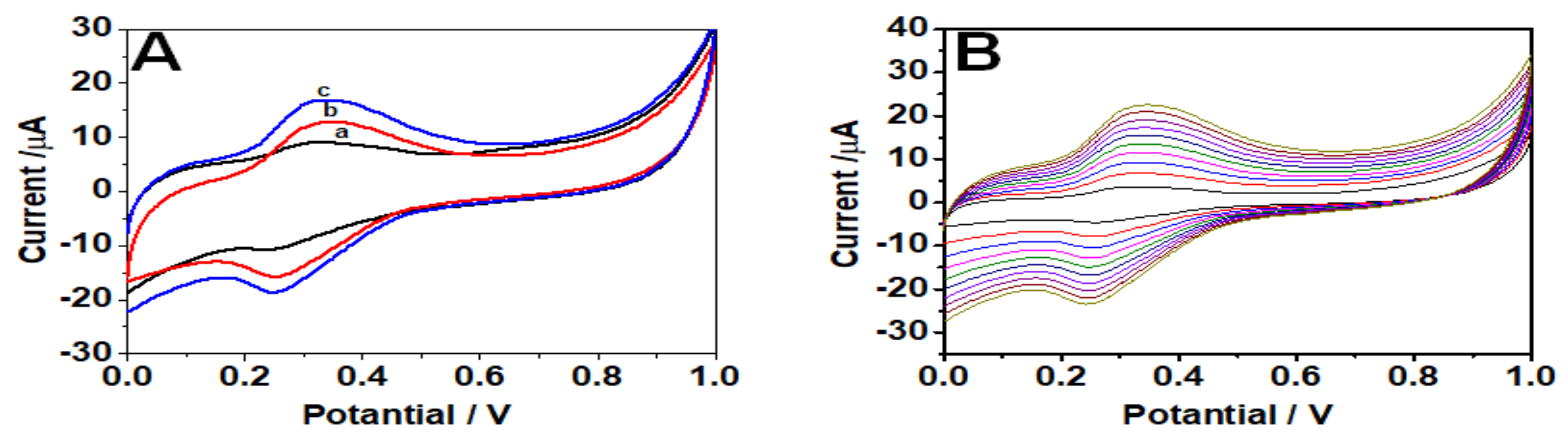

Fig.-3(A): Cyclic voltammogram of (a). nickel hexacyanoferrate electrode, (b). nickel hexacyanoferrate surface modified electrode with graphene and PPD composite electrode (c). nickel hexacyanoferrate surface modified electrode with graphene and PPD composite electrode with $0.25 \mu \mathrm{M}$ glucose and at a scan rate of $50 \mathrm{mV} / \mathrm{s}$ in $0.1 \mathrm{M}$

$\mathrm{NaCl}$ electrolyte solution ( $\mathrm{pH} 7.0$ ); (B) Cyclic voltammograms of the nickel hexacyanoferrate surface modified graphene with PPD composite electrode in the presence of altered with $0.25 \mu \mathrm{M}$ glucose at a scan rate of $50 \mathrm{mV} / \mathrm{s}$ in

$0.1 \mathrm{M} \mathrm{NaCl}$ electrolyte solution $(\mathrm{pH} 7.0)$
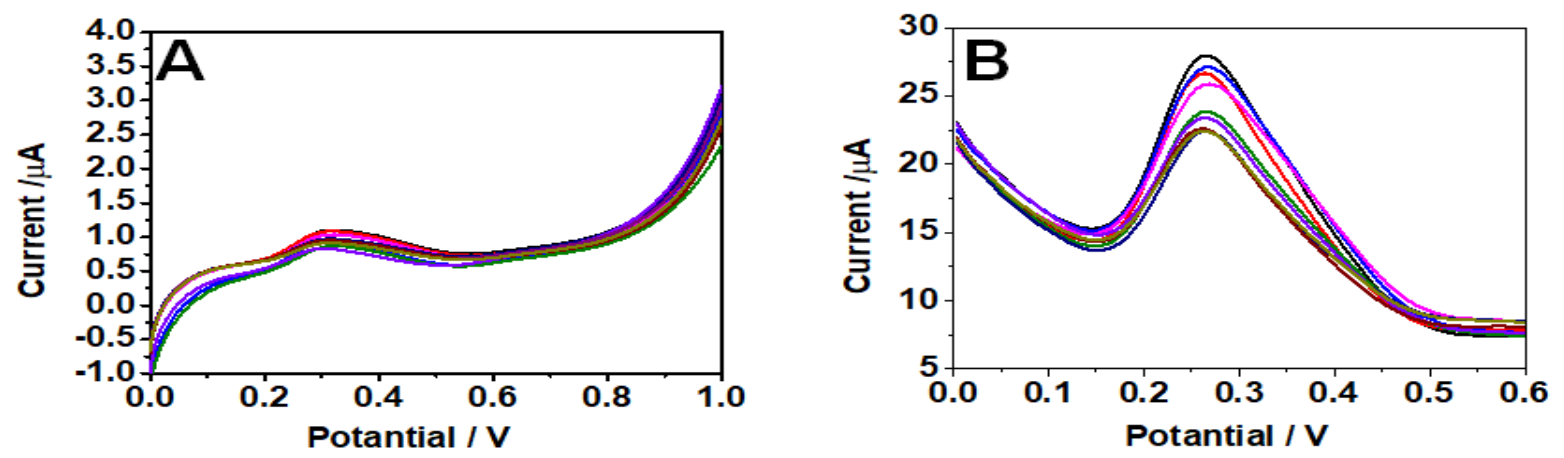

Fig.-4(A):LSVof the nickel hexacyanoferratesurface modified electrode with graphene and PPD composite electrode with $0.25 \mu \mathrm{M}$ glucose and at a scan rate of $50 \mathrm{mV} / \mathrm{s}$ in $0.1 \mathrm{M} \mathrm{NaCl}$ electrolyte solution (pH 7.0), (B) DPV of the nickel hexacyanoferratesurface modified electrode with graphene and PPD composite electrode with $0.25 \mu \mathrm{M}$ glucose and at a scan rate of $50 \mathrm{mV} / \mathrm{s}$ in $0.1 \mathrm{M} \mathrm{NaCl}$ electrolyte solution (pH 7.0).[36]

In Fig.-4A shows that the electrochemical finding signal of looks at the $0.28 \mathrm{~V}$. For the incessant additions of the nickel hexacyanoferrate surface modified electrode with graphene and PPD composite electrode with $0.25 \mu \mathrm{M}$ glucose film shows well notable anodic oxidation peaks which linearly dependent on the increasing concentrations of, respectively. This result authenticates the capability of the glucose film will be apposite for the finding of in the certain linear ranges in $0.5 \mathrm{M} \mathrm{NaCl} .^{37}$

Differential pulse voltammetry (DPV) technique was recycled to investigate the presentation of the developed biosensor for the determination of the nickel hexacyanoferrate surface modified electrode with graphene and PPD composite electrode at a scan rate of $50 \mathrm{mV} / \mathrm{s}$ in $0.1 \mathrm{M} \mathrm{NaCl}$ electrolyte solution $(\mathrm{pH}$ 7.0). Fig.-4B shows that the reduction currents of peak increased linearly with glucose concentrations in the range of $0.25 \mu \mathrm{M}$.

\section{Chronoamperometric Determination of Glucose}

The chronoamperometric of the NiHCF modified electrode towards the quantification of glucose by electrocatalytic oxidation carried out and the results are represented in Fig.-5. The figure shows the 
current-time recording achieved in a stirred solution of $0.1 \mathrm{M} \mathrm{NaCl}$ for the consecutive addition of $0.25 \mu \mathrm{M}$ glucose at consistent intervals. As NiHCF modified electrode responds very quickly to the changes in the glucose concentration. Inset in Fig.-5 shows that under the ideal conditions, the modified electrode presented a linear response to glucose. With a correlation coefficient of $0.699 .38-42$

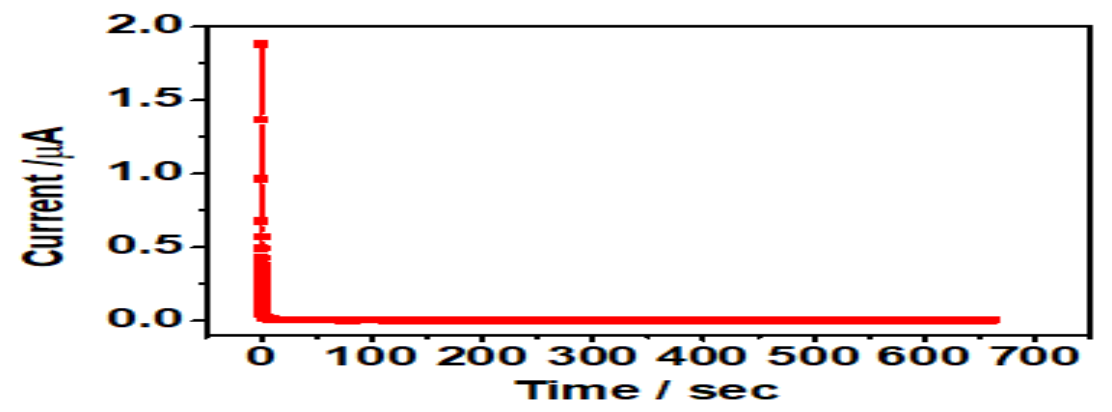

Fig.-5: Chronoamperometric current response of nickel hexacyanoferrate surface modified electrode with graphene and PPD composite electrode with $0.25 \mu \mathrm{M}$ glucose.

\section{CONCLUSION}

The results of the above studies sanction that the NiHCF modified graphene with PPD composite electrode invented using a new technique and then prove to be an outstanding amperometric sensor for the determination of glucose. amperometric and Hydrodynamic studies revealed the applicability of the modified electrode in flow inoculation investigation. And also the modified electrode was functional for the determination of a glucose in marketable samples with good accuracy. The new proposed process furnishes a new The NiHCF modified graphene with PPD composite electrode expressions very respectable catalytic activity with good linearity for glucose determination over a range of $1.7763 \times 10-4$ to $1.0 \times 10-3 \mathrm{M}$ with a detection limit of $7.0768 \times 10-6$ and a correlation coefficient of 0.699 . The modified electrode can overcome the kinetic restriction of glucose and the oxidation at a bare electrode by the catalytic process and can lower the overpotential for the oxidation reaction. The sample investigation reveals the fact that this method of determination to be appropriate for the analysis of glucose and addition of features like stability, excellent, rugosity, reproducibility and low cost of manufacture confirms the above fact and makes this sensor a definite applicant for well-organized determination of glucose.

\section{ACKNOWLEDGMENT}

This experimental work has been carried out with support from the Department of Chemistry, School of Basic Sciences at VISTAS, Chennai, Tamilnadu.India.

\section{REFERENCES}

1. I. Stone, Orthomolecular Psychiatry. 1, 82(1972), DOI: 0.1002/op.1330230122

2. S. J. R. Prabakar, Journal of Electroanalytical Chemistry, 06, 15(2008), DOI: 10.1016/j.jelechem.2008.01.020

3. Y. Andreu, S. de Marcos, J. R. Castillo, J. Galban, Talanta, 65, 1045(2005), DOI: 10.1016/j.talanta.2004.08.036

4. S. J. R. Prabakar, Talanta, 07, 31(2007), DOI: 10.1016/j.talanta.2007.02.015

5. W. Hui-Chen, L. An-Rong, Journal of Food \& Drug Analysis, 23(2), 167(2015), DOI: 10.1016/j.jfda.2015.04.001.

6. S. Yang, W. Guifang, L. Gang, D. Jingjing, and Q. Lingbo. Journal of Electrochimica Acta, 144, 1 (2014), DOI: 10.1016/j.electacta.2014.08.050

7. Y. Dilgin, G. Nisli,. Chem. Pharm. Bull., 53, 1251(2005), DOI: 10.1248/cpb.53.1251

8. A. Jain, A. Chaurasia, K. K. Verma, Talanta, 42, 779(1995), DOI: 10.1016/0039-9140(95)01477-S

9. S. M. Sultan, Talanta, 40, 593(1993), DOI:10.1016/0039-9140(93)80263-Q

10. M. M. Abdul Kamal Nazer, A. R. S. Hameed, P. Riyazuddin, Chem. Pharm. Bull., 52, 38(2004), DOI:10.1248/cpb.52.38 
RASĀYAN J. Chem.

Vol. 11 | No. 3 | 967 - 972 | July - September | 2018

11. J. Wang, T. Golden, R. Li, Anal. Chem., 60, 1642(1988), DOI: 10.1021/ac00166a038

12. S. S. L. Castro, V. R. Balbo, P. J. S. Barberia, N. R. Stradiotto, Talanta, 55, 249(2001), DOI:10.1016/S0039-9140(01)00407-6

13. S. A. Wring, J. P. Hart, Analyst (London), 117, 1215(1992), DOI:10.1039/AN9921701215

14. P. Tomcik, C. E. Banks, T. J. Davies, R. G. Compton, Anal. Chem., 76, 161(2004), DOI: $10.1021 / \mathrm{ac} 030308 \mathrm{j}$

15. D. Ravi Shankaran, N. Uehara, T. Kato, Anal. Chim. Acta, 478, 321(2003), DOI:10.1016/S00032670(02)01511-8

16. L. Cheng, G. E. Pacey, J. A. Cox, Anal. Chem., 73, 5607(2001), DOI: 10.1021/ac0105585

17. B. Nalini, S. Sriman Narayanan, Anal. Chim. Acta, 405, 93(2000), DOI: 10.1016/S00032670(99)00689-3

18. J. B. Raoof, S. Ojani, S. R. Nadmi, Electrochim. Acta, 49, 271(2004), DOI:10.1016/j.electacta.2003.08.009

19. M. K. Motlagh, M. Noroozifar, Turk. J. Chem., 28, 369(2004), DOI: 10.1016/turk/jchem/2004.

20. P. Janda, J. Weber, L. Dunsch, A. B. P. Lever, Anal. Chem., 68, 960(1996), DOI: 10.1021/ac950323r

21. Y.H. Tse, P. Janda, A. B. P. Lever, Anal. Chem., 66, 384(1994), DOI: 10.1021/ac00075a012

22. J. James, H. Gomathi, G. Prabhakara Rao, J. Electroanal. Chem., 304, 263(1991), DOI:10.1016/00220728(91)85509-N

23. D. Ravi Shankaran, S. Sriman Narayanan , Sens. Actuators B, 86, 180(2002), DOI:10.1016/S09254005(02)00171-5

24. S. Sriman Narayanan, F.Scholz, Electroanalysis, 11, 465(1999), DOI:10.1002/(SICI)15214109(199906)11:7<465::AID-ELAN465>3.0.CO;2-\#

25. P. N. Deepa, S. Sriman Narayanan, Res. J. Chem. Environ., 5, 67(2001), DOI: 10.1016/res.j.chem.2001.

26. A. Salimi, R. Hallaj, M. Ghadermazi, Talanta, 65, 888(2005), DOI: 10.1016/j.talanta.2004.08.010

27. P. Wang, Y. Yuan, X. Jing, G. Zhu, Talanta, 53, 863(2001), DOI: 10.1016/S0039-9140(00)00574-9

28. Y.D. Zhao, D.W. Pang, S. Hu, Z.L. Wang, J.K. Cheng, H.P. Dai, Talanta, 49, 751(1999), DOI: 10.1016/S0039-9140(99)00078-8

29. Munteanu F.D, Y. Okamoto, L. Gorton, Anal. Chim. Acta, 476, 43(2003), DOI: 10.1016/S00032670(02)01359-4

30. M. K. Amini, J. H. Khorasani, S. S. Khaloo, S. Tangestaninejad, Anal. Biochem., 320, 32(2003), DOI:10.1016/S0003-2697(03)00355-5

31. J. Wang, L. Angnes, C. Liang, O. Evans, Talanta, 38, 1077(1991), DOI: 10.1016/00399140(91)80222-L

32. S. M. Chen, J. Electroanal. Chem., 521, 29(2002), DOI: 10.1016/S0022-0728(02)00677-0

33. P. J. Kulesza, K. Miecznikowski, M. A. Malik, M. Galkowski, M. Chojak, K. Caban, A. Wieckowski, Electrochim. Acta, 46, 4065(2001), DOI:10.1016/S0013-4686(01)00687-9

34. D. Ravi Shankaran, S. Sriman Narayanan, Fresenius J. Anal. Chem., 365, 663(1999), DOI: $10.1007 / \mathrm{s} 002160051542$

35. A. A. Karyakin, E. A. Puganova, I. A. Budashov, I. N. Kurochkin, E. E. Karyakina, V. A. Levchenko, V. N. Matveyenko, S. D. Varfolomeyev, Anal. Chem., 76, 474(2004), DOI: 10.1021/ac0348591

36. M. Pandurangappa, N. S. Lawrence, L. Jiang, T. G. J. Jones, R. G. Compton, Analyst (London), 128, 473(2003), DOI: 10.1039/B300336C

37. A. Malinauskas, T. Ruzgas, L. Gorton, J. Electoanal. Chem., 484, 55(2000), DOI: 10.1016/S00220728(00)00059-0

38. M. A. Ansell, A. C. Zeppenfeld, K. Yoshimoto, E. B. Cogan, C. J. Page, Chem. Mater., 8, 591(1996), DOI: 10.1021/cm950346m

39. G. Gopala Rao, G. Sitarama Sastry, Anal. Chim. Acta, 56, 325(1971), DOI: 10.1016/S00032670(01)82430-2

40. M. H. Pournaghi-Azar, H. Razmi-Nerbin, J. Electroanal. Chem., 488, 17(2000), DOI: 10.1016/S00220728(00)00171-6

41. J. Wu, J. Suls, W.Sansen Electrochem. Commun., 2, 90(2000), DOI: 10.1016/S1388-2481(99)00148-4.

[RJC-3034/2018] 